\title{
Mineralogical Study of Polymer-Mortar Composites with PET Polymer by Means of Spectroscopic Analyses
}

\author{
Ahmed Soufiane Benosman ${ }^{1,2^{*}}$, Mohamed Mouli ${ }^{2}$, Hamed Taibi ${ }^{1}$, Mohamed Belbachir ${ }^{1}$, \\ Yassine Senhadji ${ }^{2}$, Ilies Behlouli ${ }^{1}$, David Houivet ${ }^{3}$ \\ ${ }^{1}$ Faculty of Science, Laboratory of Polymer Chemistry, University of Oran Es-Senia, Oran, Algeria; ${ }^{2}$ Department of Civil Engineer- \\ ing, Laboratory of Materials, ENSET, Oran, Algeria; ${ }^{3}$ Laboratory of LUSAC, University of Caen Basse-Normandie, Cherbourg- \\ Octeville, France. \\ Email: *amre20022000@yahoo.fr
}

Received December $19^{\text {th }}$, 2011; revised December 31 ${ }^{\text {st }}$, 2011; accepted February $1^{\text {st }}, 2012$

\begin{abstract}
The sheer amount of disposable bottles being produced nowadays makes it imperative to identify alternative procedures for recycling them since they are non-biodegradable. Experimental investigation on the effects of polyethylene terephthalate (PET) polymer, which is a waste material obtained by crushing of used PET bottles, on the mineralogical composition of composites after 28 days of casting are presented in this paper. Various weight fractions of cement 2.5\%, $5 \%$ and $7.5 \%$ were replaced by the same weight of PET plastic; they were then moulded into specimens and cured. The fine powder samples obtained from broken specimens were subjected to X-ray diffraction, FT-IR spectroscopy, differential thermal analysis, thermogravimetric analysis and the composites were also observed by optical microscope. Thermogravimetry (TG) and derivative thermogravimetry (DTG) were used to study the interaction between polymers and cements. Differential thermal analysis (DTA), X-ray diffraction and FT-IR were also used to investigate the cement hydration according to the additions. The results showed that an increase in polymer-cement ratio meets with a decrease in the quantity of $\mathrm{Ca}(\mathrm{OH})_{2}$; in terms of bonding, the rough surface of particle favours greater contact between PET and cement matrix and doesn't seem to have chemical interaction between the mineral species and the organic molecules which could lead to the formation of new compounds. The present study highlights the capabilities of the different methods for the analysis of composites and opened new way for the recycling of PET in polymer-mortars.
\end{abstract}

Keywords: Composite; PET Polymer; Interaction; TG/DTG; DTA; X-Ray Diffraction; FT-IR

\section{Introduction}

Polymer-modified mortars have been popular construction materials because of their excellent properties in comparison with ordinary mortars. Polymers have been used for improving mechanical properties, adhesion with substrates, or waterproofing properties of mortars and concretes. The literature agrees that the properties of polymer modified mortar and concrete depend significantly on the polymer content or polymercement ratio, that is, the mass ratio of the amount of polymer solids in a polymer-based admixture to the amount of cement in a polymer-modified mortar or concrete [1-3].

Although extensive research has been done on recycled materials, there have been very few studies concerning lightweight concrete which incorporates waste products as aggregates. The self weight of concrete elements is high and can represent a large proportion of the load on a structure [4-6]. Therefore, using lightweight

${ }^{*}$ Corresponding author. concrete with a lower density can result in significant benefits such as superior load-bearing capacity of elements, smaller cross-sections and reduced foundation sizes. A lightweight structure is also desirable in earthquake prone areas.

Polyethylene terephthalate (PET) is one of the most common consumer plastics used and is widely employed as a raw material to realize products such as blown bottles for soft-drink use and containers for the packaging of food and other consumer goods. PET bottles have taken the place of glass bottles as storing vessel of beverage due to its lightweight and easiness of handling and storage.

In 2007, it is reported a world's annual consumption of PET drink covers of approximately 10 million tons, which presents perhaps 250 milliards bottles. This number grows about up to $15 \%$ every year [7]. On the other hand, the number of recycled or returned bottles is very low. Generally, the empty PET packaging is discarded by the consumer after use and becomes PET waste (WPET). 
The major problems that this level of waste production generates initially entail storage and elimination [8]. The recycling of PET bottles and the preservation of natural resources are priority items but to date, the recycling of PET bottles as a lightweight aggregate for concrete has not been studied because of the high melting cost [9].

Researches into new and innovative uses of waste materials are continuously advancing. These research efforts try to match society's need for safe and economic disposal of waste materials. The use of recycled aggregates saves natural resources and dumping spaces, and helps to maintain a clean environment [10-16]. Thus, this current study concentrates on the waste materials without any further transformation beyond crushing, in order to minimize final material costs. Specifically plastics waste (PET) is used as substitute for conventional materials, mainly cement, in polymer-mortar composites mixes.

Even though the main effects of some polymeric additives on the mechanical properties of mortars or concrete are well established, the mechanisms responsible for these effects are not yet fully understood.

Furthermore calcium hydroxide, $\mathrm{Ca}(\mathrm{OH})_{2}$, being one of the major phases in hydrated Portland cement, occupies about $20 \%$ to $25 \%$, by volume, of the total mass [17]. It may affect the physico-mechanical properties of the hydrated cement to a considerable extent [18]. Additionally, the role which $\mathrm{Ca}(\mathrm{OH})_{2}$ plays towards the engineering properties and durability characteristics of the systems based on hydrated cement is still a matter of debate among researchers. While studying the durability aspects of cement systems, many researchers have found $\mathrm{Ca}(\mathrm{OH})_{2}$ being much more unstable in resisting the adverse environmental conditions than calcium silicate hydrate $(\mathrm{CSH})$ gel [19]. $\mathrm{Ca}(\mathrm{OH})_{2}$ is produced by the hydration of tricalcium silicate $\left(\mathrm{C}_{3} \mathrm{~S}\right)$ and dicalcium silicate $\left(\mathrm{C}_{2} \mathrm{~S}\right)$ phases of the cement. In the set Portland cement, $\mathrm{Ca}(\mathrm{OH})_{2}$ is formed with well-defined crystallinity having a definite stochiometry, which may affected by the presence of additives and admixtures [17].

In the previous work, the author studied the effects of PET polymer on the mortar properties, specifically to decrease the chloride ion penetration depth and apparent chloride ion diffusion coefficient of polymer-mortar composites. This may be explained due to the reduced volume of large-sized pores and the improved resistance to the absorption of the test solutions with an increase in polymer-cement ratio [20]. In addition, Benosman et al., [21] showed the improvement of the adherence strength and the resistance to aggressive solutions of composites using such additions. For this reason, aim of this work is to study the influence of such admixtures concerning the hydration of Portland cement by means of the mineralogical study of the composites with the same composition used in the mentioned works [20,21].
The interaction between polymers and cement Portland can be investigated through several techniques such as thermal analysis, X-ray diffraction and FT-IR. Thermogravimetry (TG), derivative thermogravimetry (DTG) and differential thermal analysis (DTA) are considered important tools for evaluating the nature of hydrated products according to different stages of cement hydration, in addition to quantifying the different phases [2225].

When cement is hydrated, its main components are transformed into hydration products, mainly calcium silicate hydrate (C-S-H gel) and portlandite. The hydration can be evaluated by measuring the mass loss of hydrated compounds up to $900^{\circ} \mathrm{C}$. The following peaks and temperature ranges have been studied when hydrated cement is heated in thermobalance and they are interpreted as described below [23,24]:

- $\sim 100^{\circ} \mathrm{C}$ : dehydration of pore water,

- $100^{\circ} \mathrm{C}-300^{\circ} \mathrm{C}$ : different stages of C-S-H dehydration,

- $\sim 500^{\circ} \mathrm{C}$ : dehydroxylation of $\mathrm{Ca}(\mathrm{OH})_{2}$,

- $\sim 700^{\circ} \mathrm{C}$ : decarbonation of $\mathrm{CaCO}_{3}$.

This study reports the results of investigations in which methods of thermal analysis, TG, DTG and DTA, were applied to investigate the effects of polymer modification on the process of hydration of portland cement by estimating $\mathrm{Ca}(\mathrm{OH})_{2}$ content and calcium hydrate content. X-ray diffraction and FT-IR were carried out to study the hydrate products of cement. Certain key proportions are also studied, in contrast with what has been undertaken in previous work $[16,26]$ in order to determine feasibility limits. Also, the analysis by the optical microscope was carried to view the arrangement of PET particles in the cement matrix. The present study highlights the capabilities of the different methods for the analysis of composites and has shown quite encouraging results and opened new way for the recycling of PET waste in polymer-mortars.

\section{Experimental}

The mortar and/or mortar-polymer composites mixtures were prepared in collaboration with two laboratories: the Laboratory of Materials, Civil Engineering Department, ENSET Oran (Algeria) and the Laboratory of Polymer Chemistry, University of Oran Es-Senia, using the following materials:

\subsection{Cement}

The cement used was a blended Portland cement type CPJ-CEM II/A (pouzzolanic cement) delivered from Zahana factory located in the western Algeria, chemical and physical properties of cement are shown in Tables $\mathbf{1}$ and 2, respectively, according to the manufactories. The chemical composition was obtained by using an X-ray 
Table 1. The chemical composition of cement.

\begin{tabular}{cc}
\hline Chemical Composition & CPJ-CEM II/A (\%) \\
\hline Loss on Ignition & 2.09 \\
$\mathrm{SiO}_{2}$ & 21.82 \\
$\mathrm{Al}_{2} \mathrm{O}_{3}$ & 6.57 \\
$\mathrm{Fe}_{2} \mathrm{O}_{3}$ & 4.01 \\
$\mathrm{CaO}$ & 63.43 \\
$\mathrm{MgO}$ & 0.21 \\
$\mathrm{SO}_{3}$ & 1.86 \\
$\mathrm{CaO}_{\text {free }}$ & 0.24 \\
\hline
\end{tabular}

fluorescence spectrometer analysis type OXFORD MDX ${ }^{1000}$.

\subsection{Polymer}

PET is a thermoplastic polyester with tensile and flexural modulus of elasticity of about 2.9 and $2.4 \mathrm{GPa}$, respectively, tensile strength up to $60 \mathrm{MPa}$ and excellent chemical resistance. It is a semi-crystalline polymer, with a melting point of about $\sim 260^{\circ} \mathrm{C}$ (Figure 1). Its density (specific gravity) is around $1.3-1.4 \mathrm{~g} / \mathrm{cm}^{3}$. The PET powder is obtained by finely crushing the drink bottles (waste plastics). After preliminary tests, polymer particles of size lower than $1 \mathrm{~mm}$ were used in this study. Figure 2 and Table 3 show the infrared spectra of PET in $\mathrm{KBr}$ pellet.

The analysis of PET was performed in the Laboratory of Applied Sciences of Cherbourg, University of Caen Basse Normandie, France, using DTA/TGA 92 Setaram equipment. The experimental conditions were: $\mathrm{N}_{2}$ gas dynamic atmosphere; heating rate $(10 \mathrm{~K} / \mathrm{min})$; alumina top-opened crucible. The samples were heated in the range of $20^{\circ} \mathrm{C}-350^{\circ} \mathrm{C}$.

\subsection{Sand}

Crushed sand obtained from Kristel quarry in Oran, West Algeria was used. The chemical properties shown in Table 4 were obtained by using an X-ray fluorescence spectrometer analysis type OXFORD MDX ${ }^{1000}$.

\subsection{Experimental Program}

Four mixtures were prepared as described in Table 5,

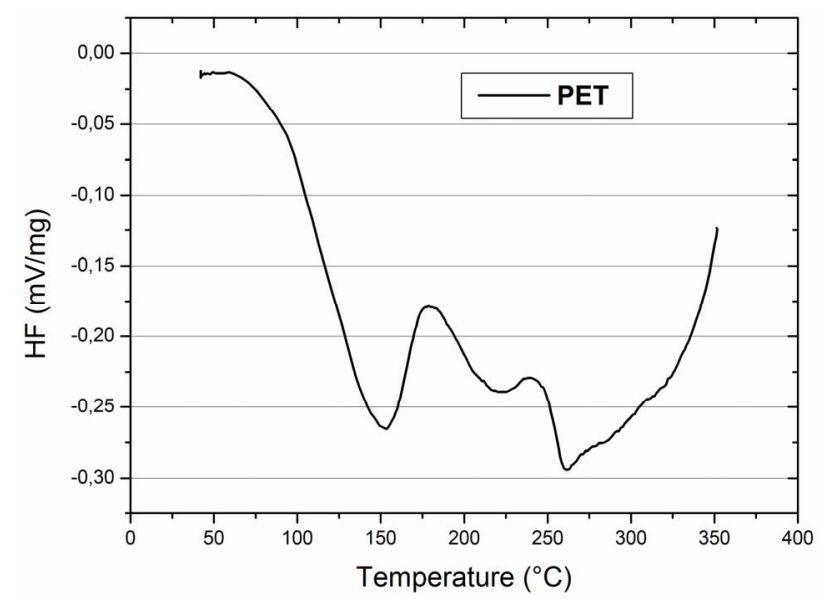

Figure 1. DTA curve at $10 \mathrm{~K} / \mathrm{min}$ of the polyethylene terephthalate PET.

Table 2. Physical properties of cement.

\begin{tabular}{ccccc}
\hline \multicolumn{2}{c}{ Setting Time (min) } & \multirow{2}{*}{ Blaine Surface Area $\left(\mathrm{cm}^{2} / \mathrm{g}\right)$} & Absolute Density $\left(\mathrm{g} / \mathrm{cm}^{3}\right)$ & \multicolumn{2}{c}{ Compressive Strength (MPa) } \\
\cline { 1 - 1 } Initial & Final & & 28 -days \\
\hline 120 & 200 & 2987 & 3.09 & 32.5 \\
\hline
\end{tabular}

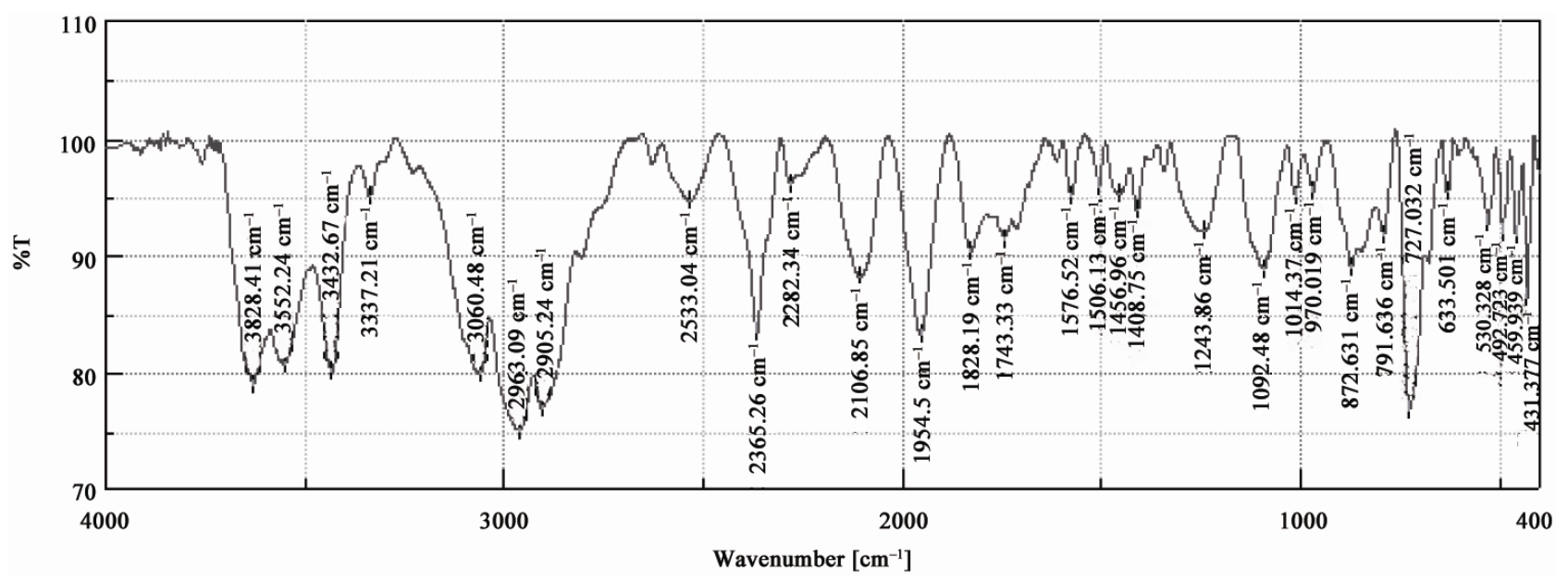

Figure 2. Fourier-transform infrared spectrum of PET polymer in KBr pellet. 
Table 3. Fourier-transform infrared table of PET polymer in KBr pellet.

\begin{tabular}{ll}
\hline \multicolumn{1}{c}{$\left(\mathbf{c m}^{-1}\right)$} & \multicolumn{1}{c}{ Bands identification } \\
\hline 872.63 & Glternating deformation of benzene, out of the plane (para-disubstituted) \\
1092.48 & $-\mathrm{C}-\mathrm{O}$ \\
$1576.52-1660.2$ & $\mathrm{C}=\mathrm{C}$, aromatic character \\
1743.33 & $-\mathrm{COO}-$ \\
$2963.09-2905.24$ & $-\mathrm{CH}_{2^{-}}$ \\
3060.48 & $\mathrm{CH}$, benzene group \\
\hline
\end{tabular}

Table 4. The chemical composition of sand.

\begin{tabular}{cc}
\hline Chemical Composition & Sand (\%) \\
\hline Loss on ignition & 43.83 \\
$\mathrm{SiO}_{2}$ & 0.77 \\
$\mathrm{Al}_{2} \mathrm{O}_{3}$ & 0.11 \\
$\mathrm{Fe}_{2} \mathrm{O}_{3}$ & 0.36 \\
$\mathrm{CaO}$ & 54.71 \\
$\mathrm{MgO}$ & 0.21 \\
$\mathrm{SO}_{3}$ & $\mathrm{Nil}$ \\
$\mathrm{Chlorures}$ & $\mathrm{Nil}$ \\
\hline
\end{tabular}

which are the composites with the same proportions used in the previous works [20,21], as explained in the introduction. The materials were weighed and mixed in a planetary type mortar mixer. The mortar mixes had proportions of 1 binder: 3 Sand (by weight). The binder consisted of cement and polyethylene terephthalate. The water to binder ratio was kept constant at 0.5 . The physical properties of the pastes of mortars were determined in accordance with EN 196-3 [27].

The preparation for TG/DTG, DTA, X-ray diffraction and FT-IR analysis was carried out using agate crucible, in which the mortar or composite was manually ground until the size of particles was lower than $0.160 \mathrm{~mm}$. For the prevention of carbonation and maintenance of relative humidity, all specimens were stored in the vacuum up to the time when the test started.

The analyses were performed in the Laboratory of Polymer Chemistry, University of Oran, using Labsys TGA SETARAM Thermogravimetric Analyzer equipment, easy to use (ambient to $1600^{\circ} \mathrm{C}$ ). The experimental conditions were: He gas dynamic atmosphere; heating rate $\left(10^{\circ} \mathrm{C} \cdot \mathrm{min}^{-1}\right)$. The samples were heated in the range of $20^{\circ} \mathrm{C}-1100^{\circ} \mathrm{C}$ at a constant rate. The $\mathrm{Ca}(\mathrm{OH})_{2}$ and calcite were estimated from the weight losses measured in the TG curve between the initial and final temperature of the corresponding TG peak.

The composites were submitted to thermal analysis in a DTA equipment, type Linseis mark DTA L62, in the Laboratory of Materials, ENSET Oran. The experimental conditions were 1) continuous heating from $25^{\circ} \mathrm{C}$ to $\sim 1100^{\circ} \mathrm{C}$; 2) heating rate: $10^{\circ} \mathrm{C} / \mathrm{min}$; 3) alumina, topopened crucible. DTA curves were obtained.

XRD was used to identify the polycrystalline phases of cement and hardened cement paste by means of the recognition of the X-ray patterns that are unique for each of the crystalline phases. The qualitative XRD investigation was performed in a Philips PW $1710 \mathrm{X}$-ray diffractometer with $\mathrm{Cu} \mathrm{K} \alpha$ radiation and $2 \theta$ scanning, ranging between $5^{\circ}$ and $80^{\circ}$ of $2 \theta$.

The composites were analyzed by an optical microscope, type Keyence VH-5911 commissioned by Microvision software, available at the Laboratory LMDC of INSA, Toulouse, France.

A FT/IR-4200 Type A, Photometrec Fourier-transform infrared spectrometer was used, and the mortar/composite cement were analyzed in $\mathrm{KBr}$ pellets. The spectra were traced in the range of $4000-400 \mathrm{~cm}^{-1}$ (wave number), and the band intensities were expressed in transmittance (\%).

\section{Results and Discussion}

\subsection{Thermal Analysis (DTA, TG/DTG)}

The DTA and TG curves obtained in all of the tests are typical of hydrated cement composites containing carbonate phases. Three major endothermic reactions occurred during the heating of the samples: 1 ) release of the evaporable and part of the adsorbed water (CSH and ettringite) at $110^{\circ} \mathrm{C}$ approximately; 2) $\mathrm{Ca}(\mathrm{OH})_{2}$ dehydration, between $450^{\circ} \mathrm{C}$ and $510^{\circ} \mathrm{C}$; 3) decomposition of the carbonate phases at $\sim 850^{\circ} \mathrm{C}-900^{\circ} \mathrm{C}$ (Figure 3). As shown in Figure 4, PET polymer strongly influences the DTA curve, causing 1) enlargement of the exothermic shoulder at $\sim 200^{\circ} \mathrm{C}-420^{\circ} \mathrm{C}$; 2) decreasing of the endothermic peak intensity and weight loss on the dehydration of calcium hydroxide; 3) sharp changes in the curves at temperatures higher than $510^{\circ} \mathrm{C}$ (in most cases, an endothermic peak at $580^{\circ} \mathrm{C}$ and three exothermic shoulders at $820^{\circ} \mathrm{C}-840^{\circ} \mathrm{C}, 620^{\circ} \mathrm{C}-660^{\circ} \mathrm{C}$ and $540^{\circ} \mathrm{C}$ were detected); 4) enlargement of the endothermic peak intensity at $620^{\circ} \mathrm{C}-780^{\circ} \mathrm{C}$ and decreasing of the peak temperature 
Table 5. Mix proportions and physical properties of polymer-mortar composites.

\begin{tabular}{cccccc}
\hline Mix Design & Polymer-Cement Ratios (\%) & Water Demand for Standard Consistency $(\%)$ & Setting Time $(\mathrm{min})$ & Density $\left(\mathrm{g} / \mathrm{cm}^{3}\right)$ \\
\hline / & & & Initial & Final & \\
PET 0 & 0 & 24.5 & 120 & 200 & 2.28 \\
PET2.5 & 2.5 & 25 & 125 & 205 & 2.23 \\
PET5.0 & 5.0 & 25.5 & 130 & 210 & 2.22 \\
PET7.5 & 7.5 & 26 & 145 & 225 & 2.21 \\
\hline
\end{tabular}

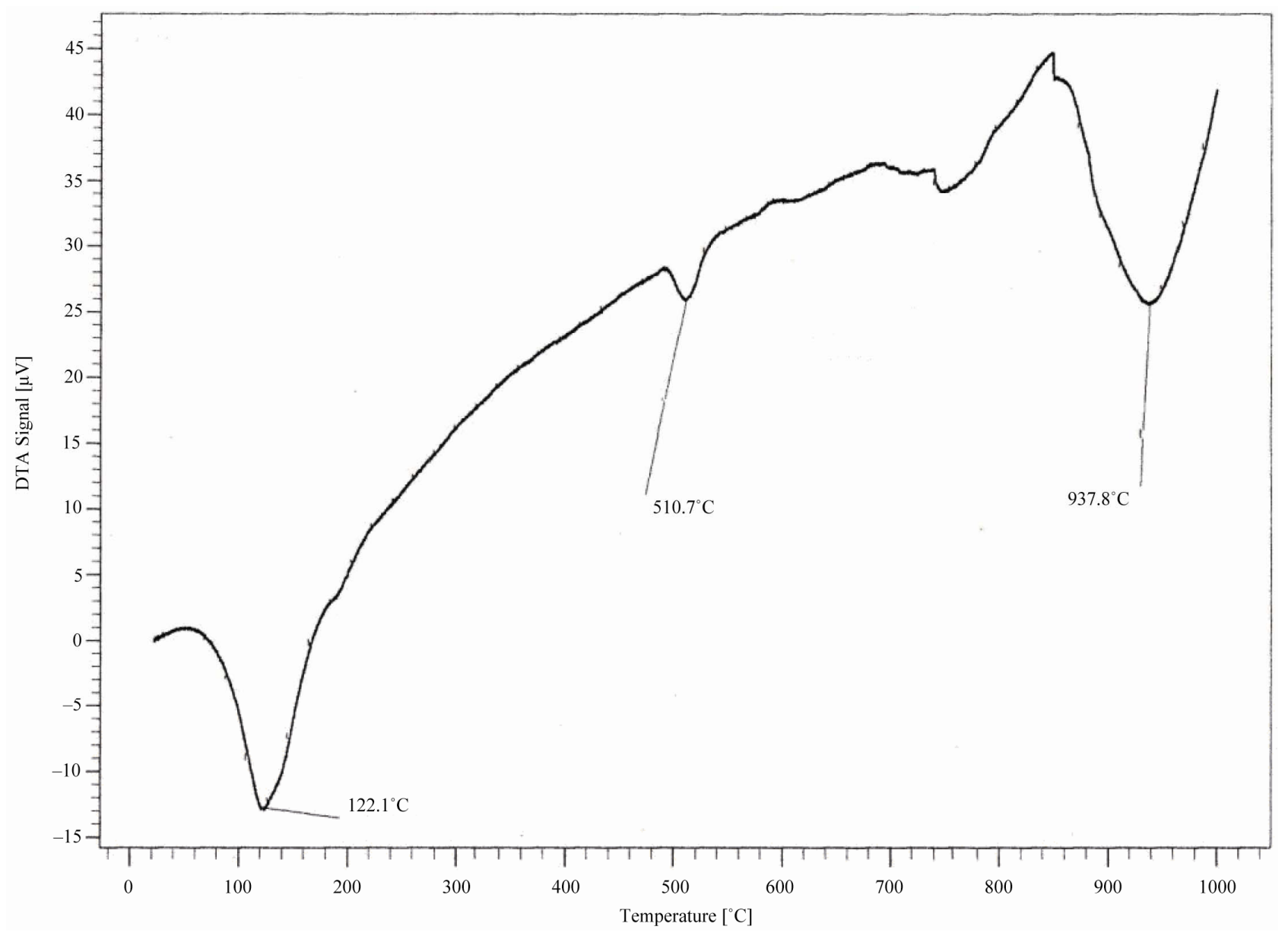

Figure 3. DTA curve at $10^{\circ} \mathrm{C} / \mathrm{min}$ of an unmodified mortar PET0.

(from about $\sim 937^{\circ} \mathrm{C}$ to $\sim 926^{\circ} \mathrm{C}$ ); and e) decreasing of the weight loss in the latter temperature range. These results comply with an early study of Silva et al. [28], in which EVA copolymer strongly influences the DTA/TG curves.

Figure 5(a) shows the TG curves of mortar without polymer PET0. It can be seen that TG/dTG curves for this mortar consist of four zones:

$\sim 40^{\circ} \mathrm{C}-123.3^{\circ} \mathrm{C}$ : dehydration of pore water,

$\sim 123.3^{\circ} \mathrm{C}-420^{\circ} \mathrm{C}$ : dehydration of calcium silicate hydrates,

$\sim 420^{\circ} \mathrm{C}-510^{\circ} \mathrm{C}$ : dehydroxylation of calcium hydroxide,

$\sim 840^{\circ} \mathrm{C}$ : decarbonation of $\mathrm{CaCO}_{3}$.
Figure 5(b), Figures 6(a) and 6(b) show TG curves of composites with PET polymer addition of 2.5\%, 5\% and 7.5\% (polymeric solids). The TG curves obtained in these tests are typical of hydrated cement composites containing carbonate phases and PET polymeric admixtures influences. As it is shown, the curves can be divided into five major parts, according to different reactions:

$\sim 123.3^{\circ} \mathrm{C}$ : dehydration of pore water,

$\sim 123.3^{\circ} \mathrm{C}-345^{\circ} \mathrm{C}$ : dehydration of calcium silicate hydrates,

$\sim 490^{\circ} \mathrm{C}-517^{\circ} \mathrm{C}$ : dehydroxylation of calcium hydroxide,

$\sim 650^{\circ} \mathrm{C}-780^{\circ} \mathrm{C}$ : Enlargement of the endothermic peak 


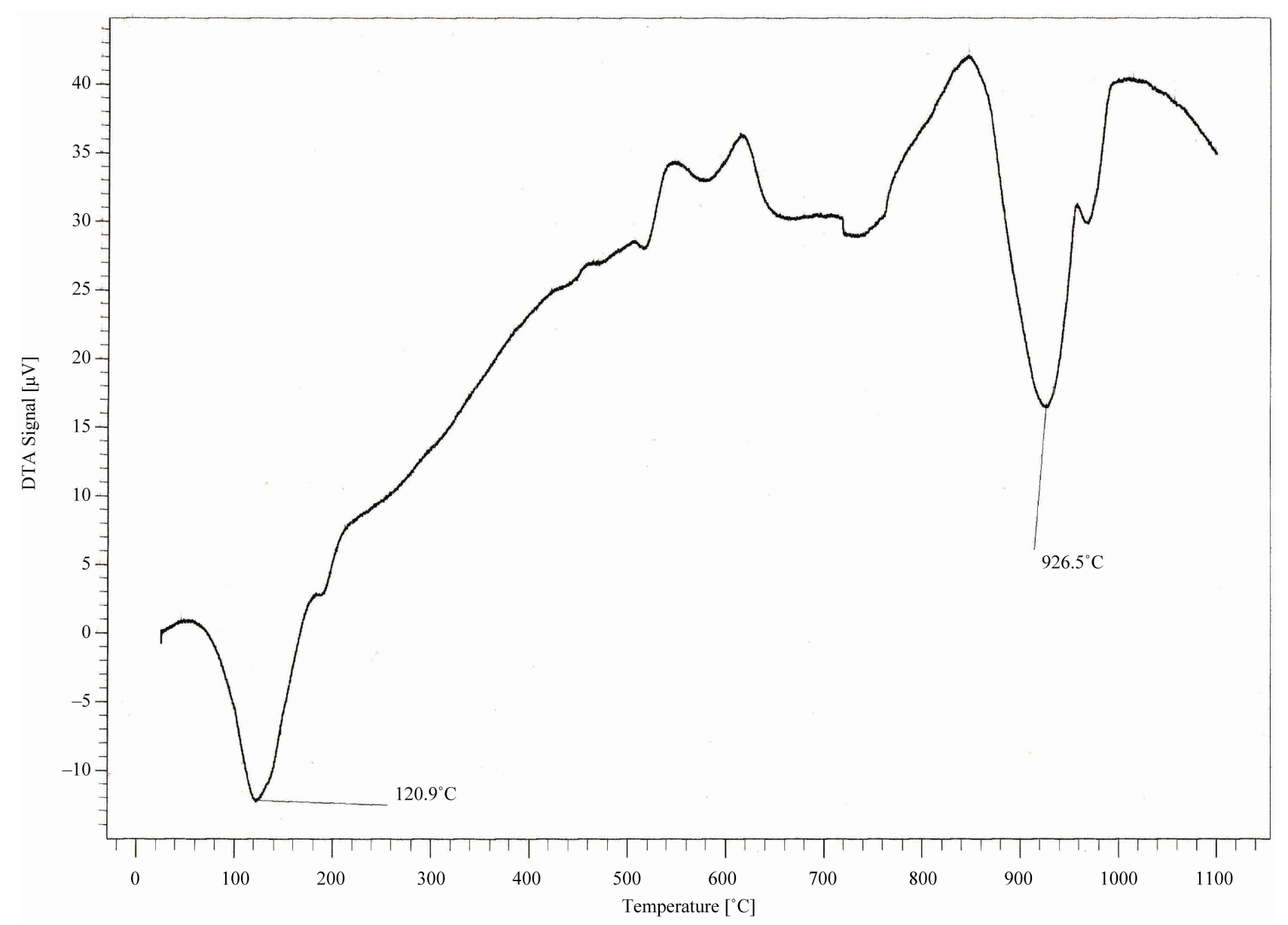

Figure 4. DTA curve at $10^{\circ} \mathrm{C} / \mathrm{min}$ of the composite PET5.

intensity; as it was found from the DTA analyses.

$\sim 800^{\circ} \mathrm{C}$ : decarbonation of $\mathrm{CaCO}_{3}$.

All the weight loss data are expressed as a function of the ignited weight of the sample, as suggested by Taylor [29]. The calcium hydroxide content was determined from the following equation:

$$
\mathrm{CH}(\%)=\mathrm{WL}_{\mathrm{CH}}(\%) \times \frac{\mathrm{MW}_{\mathrm{CH}}}{\mathrm{MW}_{\mathrm{H}}}
$$

where $\mathrm{CH}(\%)$ is the content of $\mathrm{Ca}(\mathrm{OH})_{2}$ (in weight basis), $\mathrm{WL}_{\mathrm{CH}}(\%)$ is the weight loss occurred during the dehydration of calcium hydroxide (in weight basis), $\mathrm{MW}_{\mathrm{CH}}$ is the molar weight of calcium hydroxide and $\mathrm{MW}_{\mathrm{H}}$ is the molar weight of water. Since the exact stoichiometry of decomposition reactions of the carbonate phases is not known, the results are expressed in function of the weight of $\mathrm{CO}_{2}$ gas released during the decomposition, and not as carbonate phase's content.

When one adds the PET to the composite there is a diminution of the calcium hydroxide $(\mathrm{CH})$ content and an increase of the dehydration temperature, as can be seen in Figures 7(a) and (b). Also, Silva et al. [28] demon- strated that EVA polymer strongly reduces the $\mathrm{CH}$ content. Figure 8 shows that PET polymer sharply decreases the quantity of carbonate phases in the composites, measured by TG/DTG.

Because when the rate of substitution of PET increases, there is less formation of portlandite $\mathrm{Ca}(\mathrm{OH})_{2}$, which is mainly the result of the following reaction:

$$
\mathrm{C}_{3} \mathrm{~S} \text { and } \mathrm{C}_{2} \mathrm{~S}+\mathrm{H}_{2} \mathrm{O} \rightarrow \mathrm{C}-\mathrm{S}-\mathrm{H}+\mathrm{Ca}(\mathrm{OH})_{2}
$$

\subsection{XRD Analyses}

The XRD results show some qualitative differences in the hydration rate due to the incorporation of PET polymer. Figure 9 shows the X-ray patterns of the composites with $7.5 \%$ of polyethylene terephthalate, and composites without polymer PET0. The main compounds observed are $\mathrm{Ca}(\mathrm{OH})_{2}$ in the form of portlandite, a big amount of $\mathrm{CaCO}_{3}$ resulting from carbonation of $\mathrm{Ca}(\mathrm{OH})_{2}$ and calcium silicate anhydrous. The peak intensity in the region $2 \theta=18^{\circ}-18.1^{\circ}[30,31]$ has been considered as a measure of the quantity of $\mathrm{Ca}(\mathrm{OH})_{2}$ [32].

So, it is also noted here that at a polymer-cement ratio of $7.5 \%$ a slight increase in the peak intensity compared 


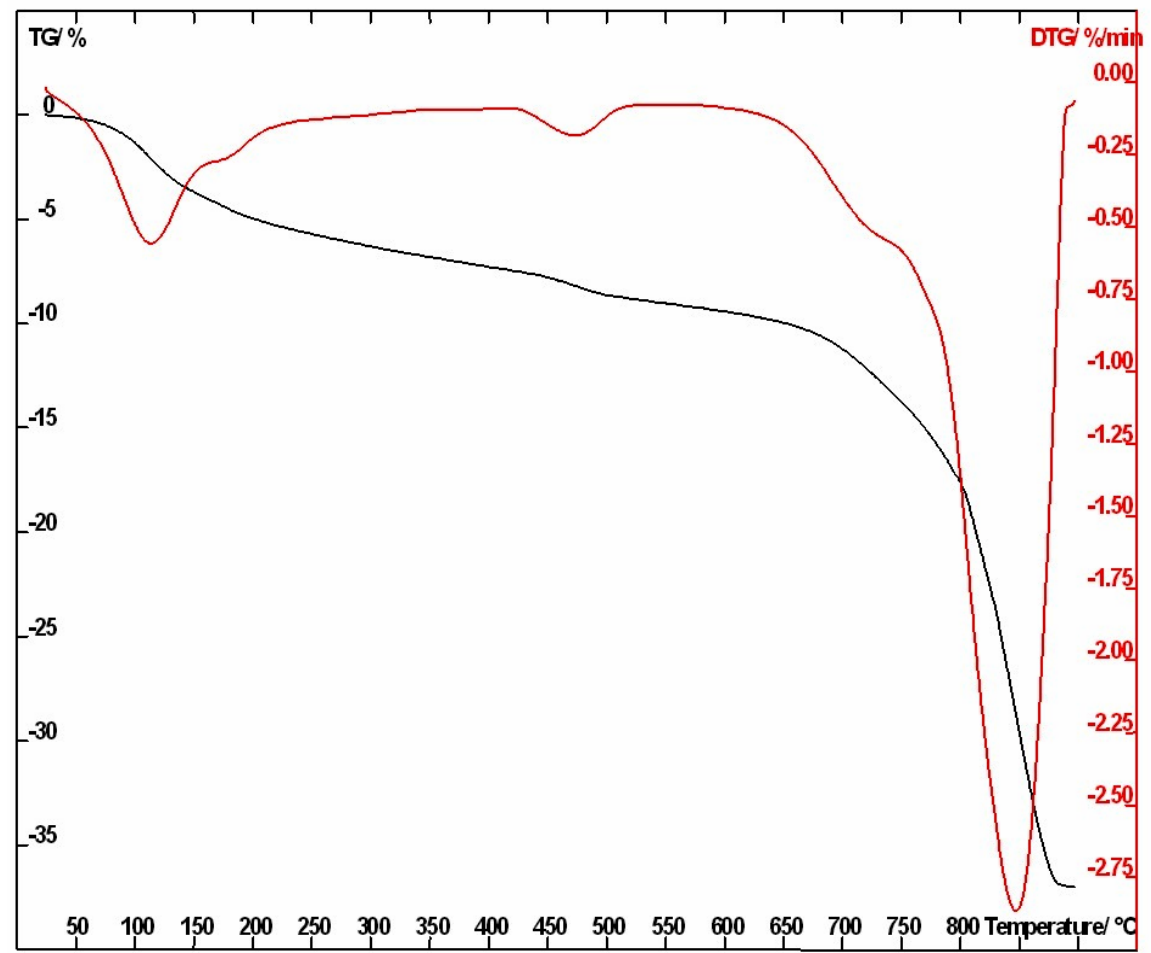

(a)

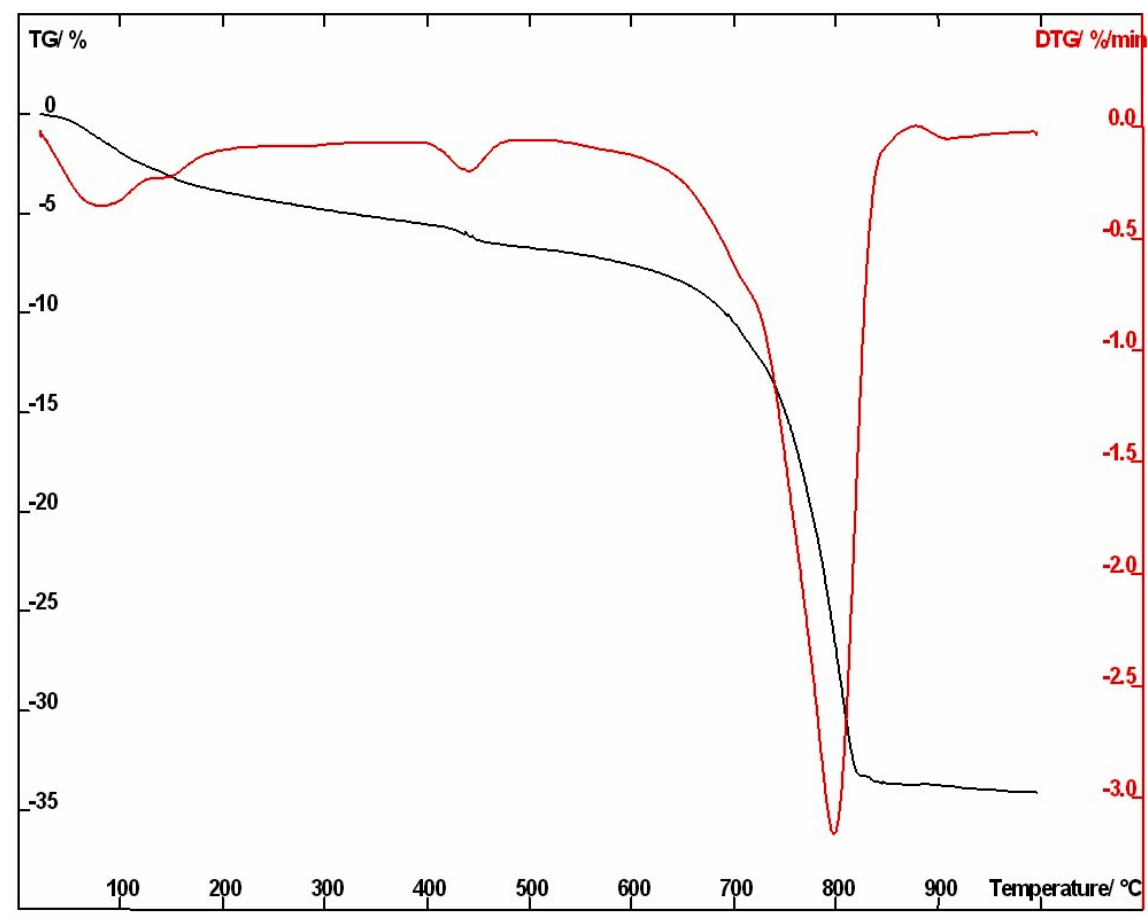

(b)

Figure 5. TG/DTG curves at $10^{\circ} \mathrm{C} \cdot \mathrm{min}^{-1}$ of unmodified mortar CPJ-PET0 (a) and the composite PET2.5 (b).

to the unmodified mortar is observed. Further, $\mathrm{Ca}(\mathrm{OH})_{2}$ crystals may possibly produce sharper reflection in the presence of PET polymer due to a change in the orientation pattern of the crystals. This sharper reflection offsets the effect gained by the lowered quantity of $\mathrm{Ca}(\mathrm{OH})_{2}$, and so the peak intensity at a polymer-cement ratio of $7.5 \%$ appears at an increased level compared to that of the unmodified mortar. These results are in line with 


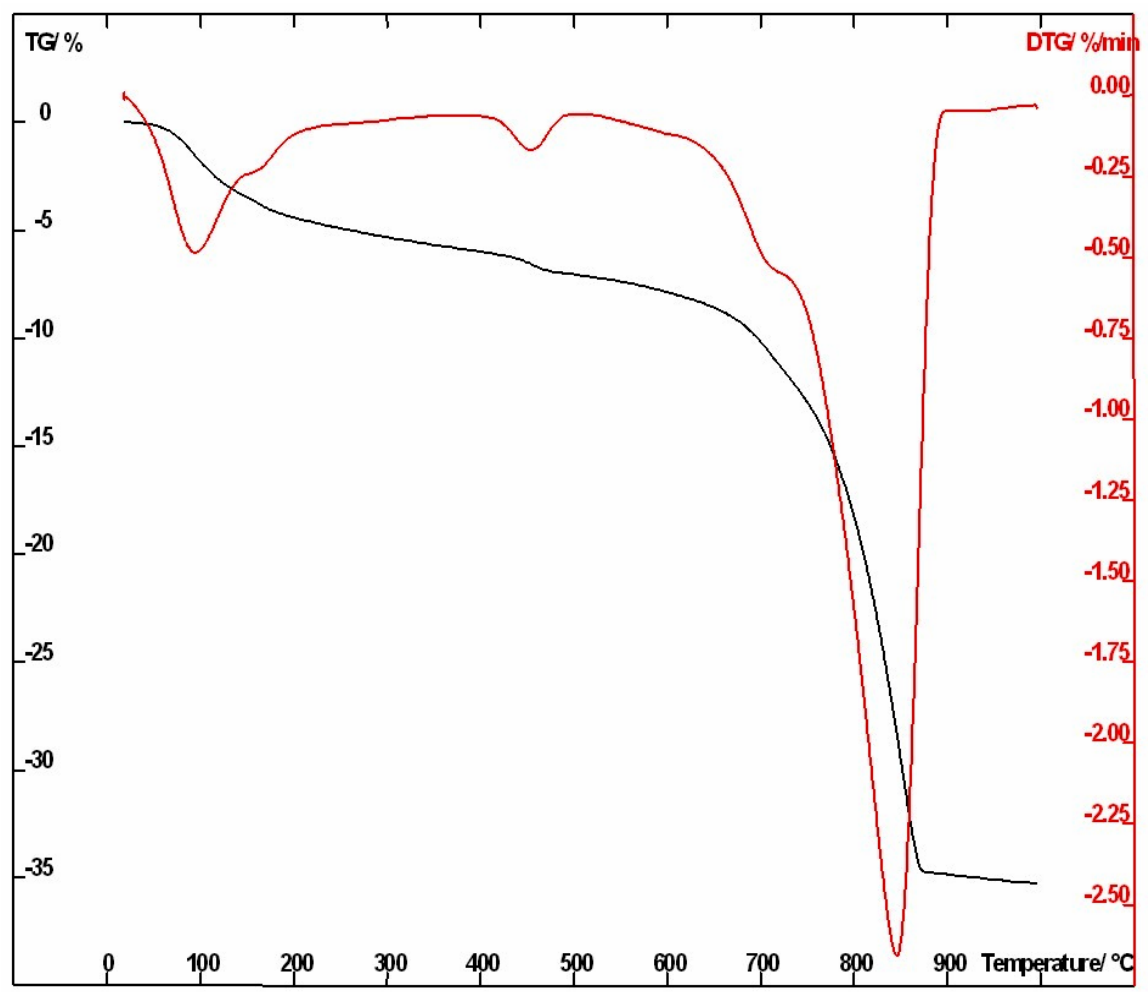

(a)

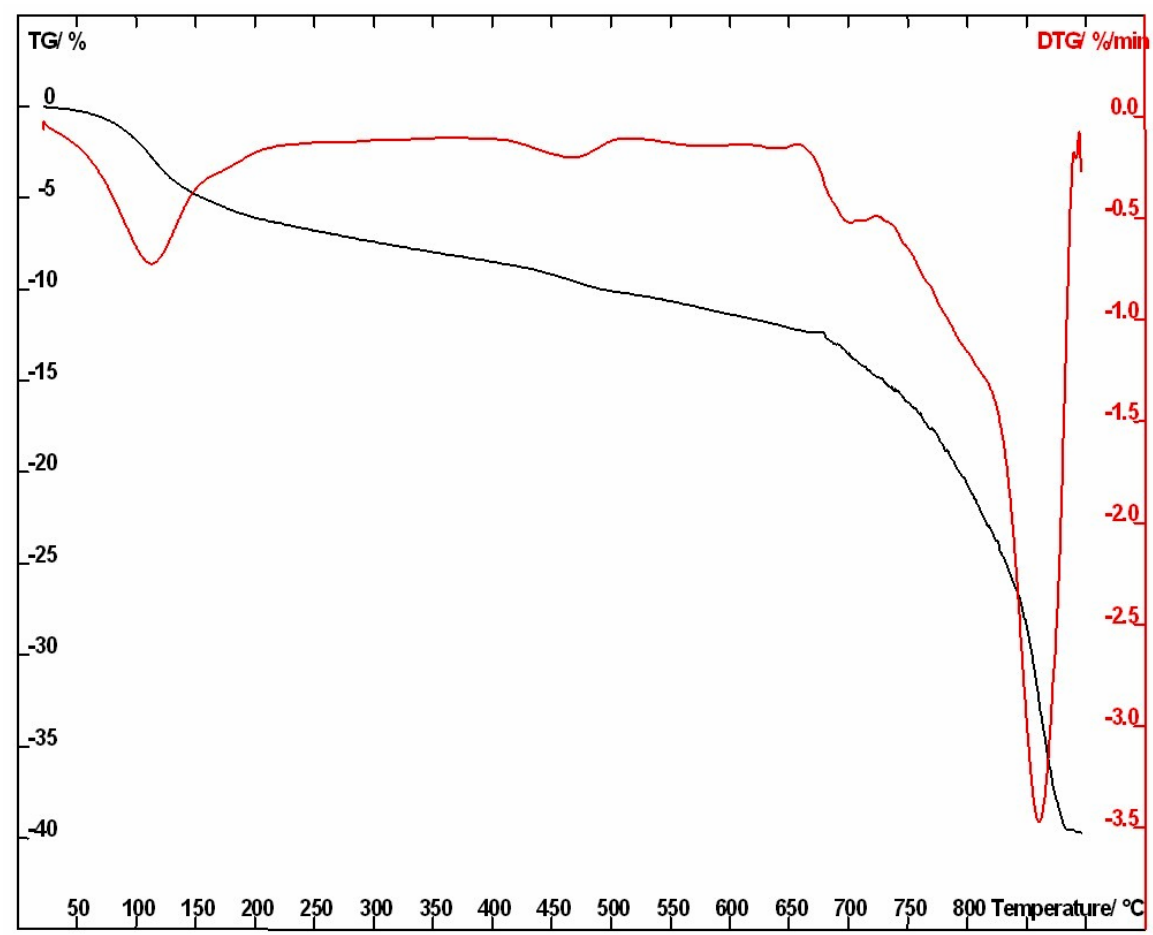

(b)

Figure 6. TG/DTG curves at $10^{\circ} \mathrm{C} \cdot \mathrm{min}^{-1}$ of the composite PET5 (a) and the composite 7.5 (b).

those of some previous research's [19,26,31].

On the basis of the experience gained by DTA/TGA analysis, it is possible to explain this variation in terms of the fact that the PET addition causes a progressive decrease in the amount of portlandite $\mathrm{Ca}(\mathrm{OH})_{2}$ in the composites compared to unmodified mortar. 


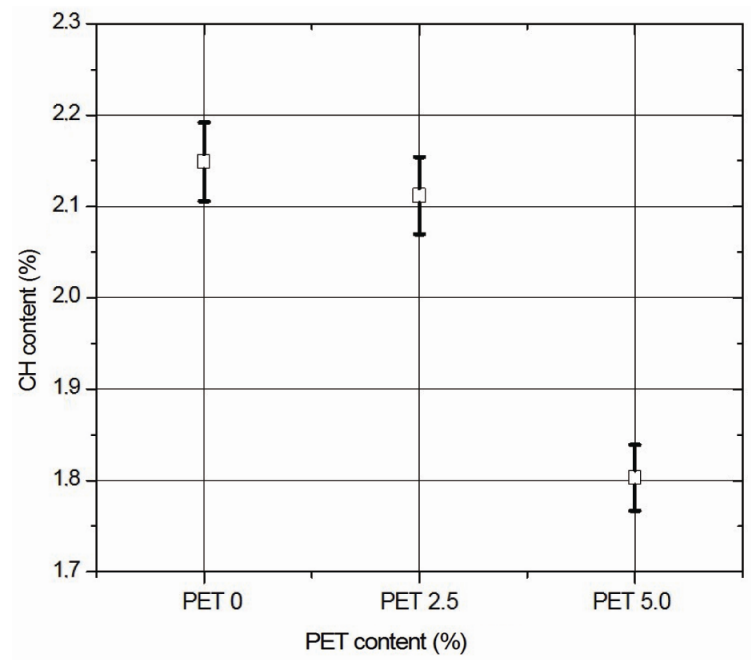

(a)

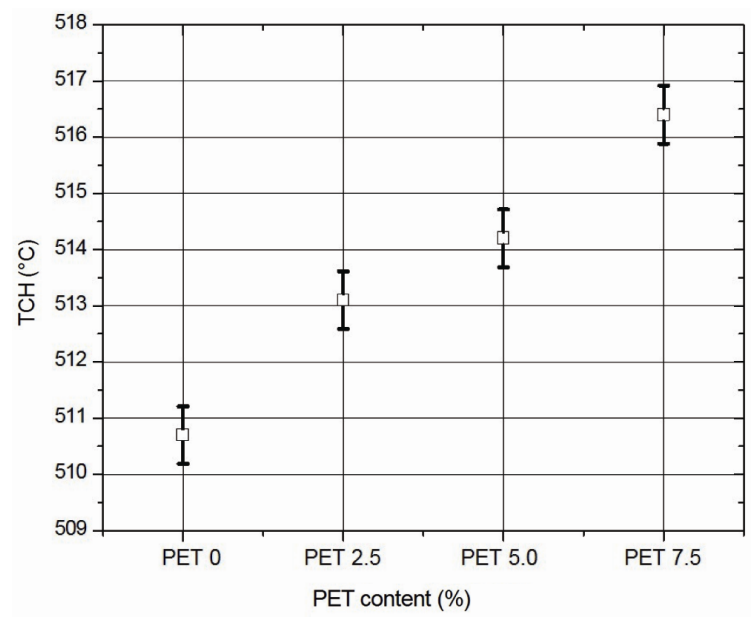

(b)

Figure 7. Effect of PET content on the calcium hydroxide content $(\mathrm{CH})$ (a) and its dehydration temperature (TCH) (b).

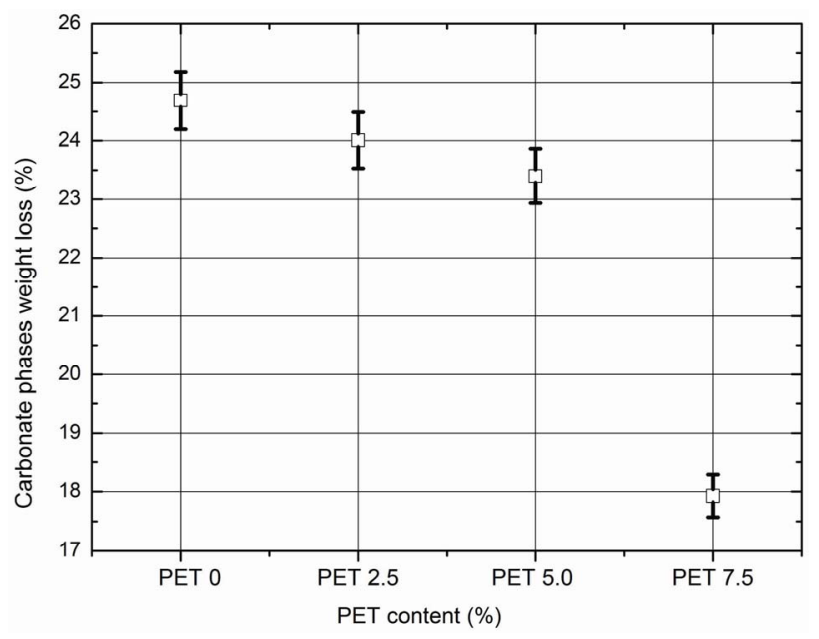

Figure 8. Effect of PET content on the weight loss due to carbonate phases' decomposition.

\subsection{The Optical Microscope Results}

Figure 10 shows optical micrograph of the composite containing the PET particles. In terms of bonding, the rough surface of particle favours greater contact between PET and cement matrix. The particles appear well covered by cement matrix. Furthermore, Benazzouk et al., [33] found that there is a good adherence between rubber particles and cement matrix. So, the introduction of the PET addition leads to a densification of the cement matrix, which serves to improve material strength and durability $[21,34]$.

\subsection{FT-IR Analyses of Hydrated Cement and PET Polymer}

The FT-IR spectra of the PET0 and PET7.5 composite cement hydrated up to 28 days and PET polymer are presented in Figure 11. The major changes of the FTIR spectra in the hydrated cement are:

Calcium hydroxide bands $\left(\sim 3638 \mathrm{~cm}^{-1}\right)$ and also for the free OH groups, combined and adsorbed water of C$\mathrm{S}-\mathrm{H}, \mathrm{AFm}$ and AFt phases $\left(3451.96 \mathrm{~cm}^{-1}\right)$, molecular water $\left(3440-3446\right.$ and $\left.1640-1654 \mathrm{~cm}^{-1}\right)$, carbonate phases $\left(\sim 1427,874.56\right.$ and $\left.713.5 \mathrm{~cm}^{-1}\right)$. The broad band at $\sim 1020-1018 \mathrm{~cm}^{-1}$ arises from C-S-H vibrations, in agreement with those reported by Martinez-Ramirez [35]. As can be seen in Figures 2, 11 and Table 3, PET polymer doesn't cause any modifications in the spectra profile.

The PET0 and PET7.5 composite have the similar IR spectra (Figure 11). So, there isn't any chemical interaction between the mineral species and the organic molecules which could lead to the formation of new compounds, in agreement with XRD analysis.

\section{Conclusions}

The following conclusion can be drawn from the obtained experimental data:

From the thermogravimetric investigations performed, showed in the TG/DTG and DTA curves, it is possible to conclude that polymeric additions have influenced the cement hydration.

The qualitative XRD investigation revealed that a lower intensity of $\mathrm{Ca}(\mathrm{OH})_{2}$ (in the region $2 \theta=18^{\circ}$ ) was obtained in the presence of PET, compared to mortar without polymer. Similarly, we found a decrease in the $\mathrm{Ca}(\mathrm{OH})_{2}$ content in the TG analyses for the modified mortar with polymer addition. As it can be seen, composite with 5\% polymer content presented the lowest $\mathrm{Ca}(\mathrm{OH})_{2}$ compared with the other composites.

The FT-IR analyses exhibited that there isn't any chemical interaction between the mineral species and the organic molecules which could lead to the formation of 


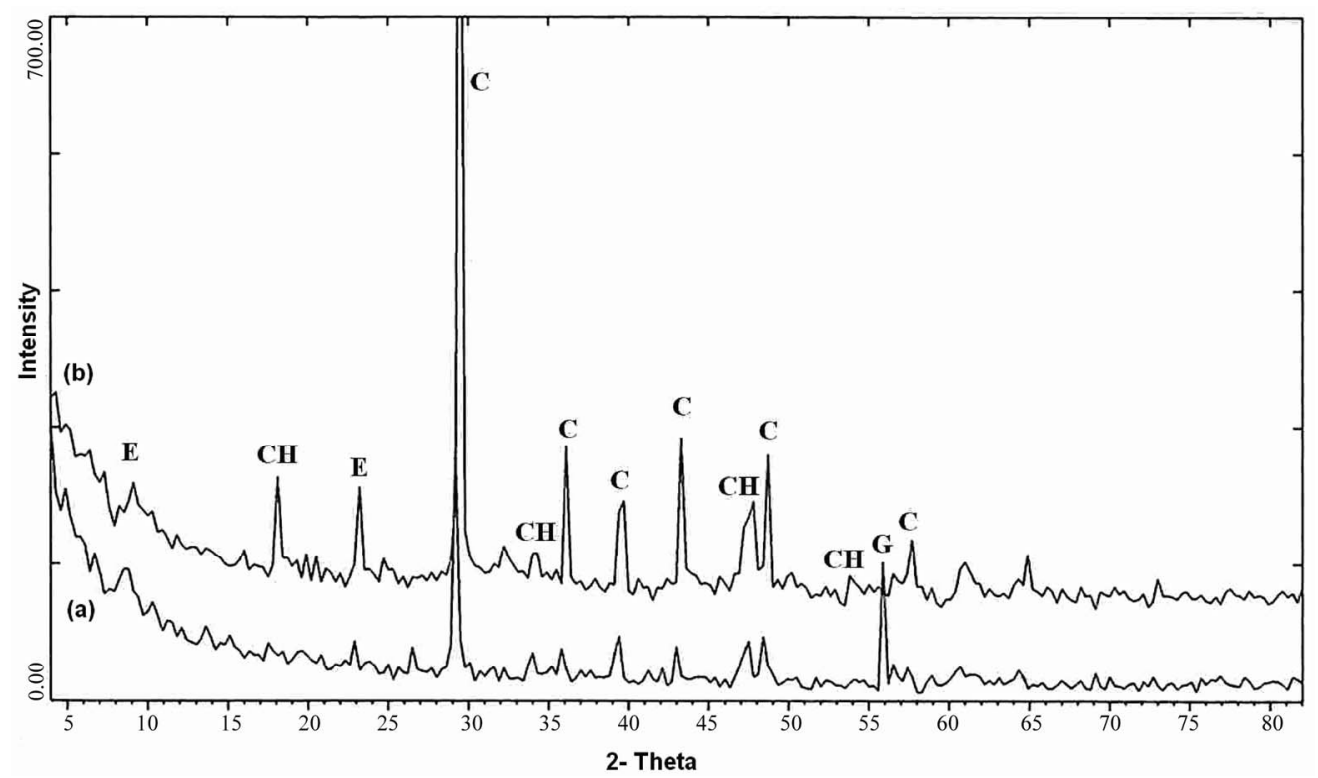

Figure 9. XRD patterns of the PETO (a) and PET 7.5 (b) composites after 28 days of Hydration. $\mathrm{CH}$, portlandite (Ca(OH) $\left.)_{2}\right)$; $\mathrm{C}$, calcium carbonate $\left(\mathrm{CaCO}_{3}\right)$; E, ettringite $\left(\mathrm{Ca}_{6}\left[\mathrm{Al}(\mathrm{OH})_{6}\right]_{2}\left(\mathrm{SO}_{4}\right)_{3} \cdot 26 \mathrm{H}_{2} \mathrm{O}\right) ; \mathrm{G}$, gypsum $\left(\mathrm{CaSO}_{4} \cdot 2 \mathrm{H}_{2} \mathrm{O}\right)$.

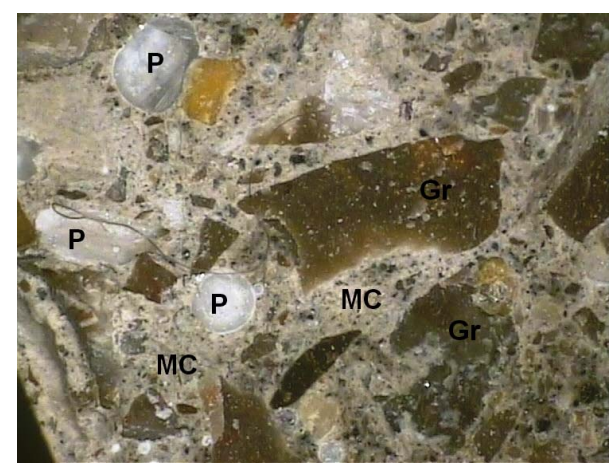

Figure 10. Optical micrograph of composite containing the PET particles at 360 days-adherence of particle additives to the matrix (magnification X25). P-PET, Gr-aggregate, MC-cement matrix. new compounds, in agreement with XRD analysis.

In terms of bonding, the rough surface of particle favours greater contact between PET and cement matrix. The particles appear well covered by cement matrix. So, the introduction of the PET addition leads to a densification of the cement matrix, which serves to improve material strength and durability.

The application in civil construction of cement composite-based PET wastes appears to be feasible considering the results obtained from analysis of its properties. This study contributes toward the program of PET wastes recycling and pollution reduction. To conclude, studies on the durability of the composite when exposed to aggressive environment, like resistance to acid, sulfate at-

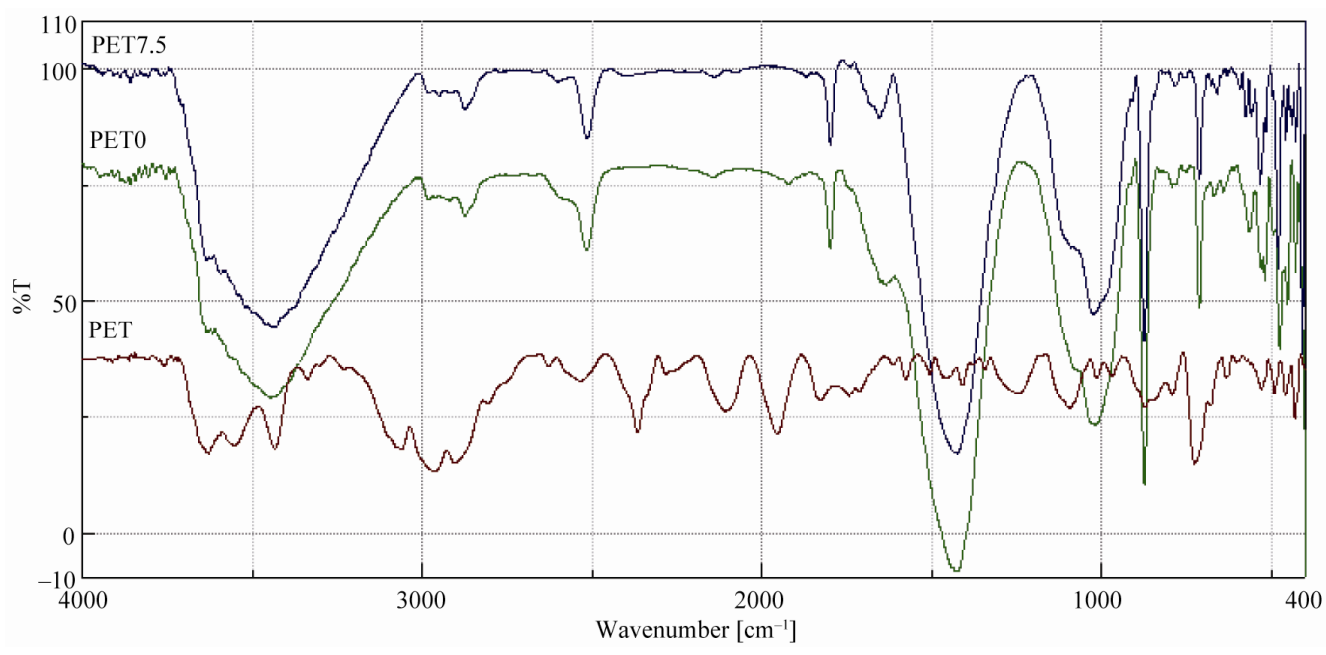

Figure 11. FT-IR spectra of PET0 and PET7.5 composite cured for 28 days and PET polymer. 
tack and corrosion have started and displayed encourageing first results.

The durability of the concrete is an important engineering property. It determines the service life of concrete structures very significantly. Some conclusions were stated by the author in his previous study $[20,21]$ :

- The resistance to acids solutions explained by the mass loss of polymer-mortar composites exposed to $\mathrm{HCl}$ and $\mathrm{CH}_{3} \mathrm{COOH}$ solution were lower than those of unmodified mortar.

- The basic solutions are harmless to composite materials.

- The resistance to chloride ion penetration was improved [20].

Such mortars can be recommended as effective materials for preventing the chloride-induced corrosion of reinforcing steel in various concrete structures and towards the chemical resistance to typical reagents for industrials uses.

\section{Acknowledgements}

The authors acknowledge the financial support from the Ministry of Higher Education and Scientific Research of Algeria, under the grants CNEPRU J0405520060009.

\section{REFERENCES}

[1] Y. Ohama, "Polymer Based Admixtures," Cement and Concrete Composite, Vol. 20, No. 2-3, 1998, pp. 189-212. doi:10.1016/S0958-9465(97)00065-6

[2] Y. Ohama, "Recent Progress in Concrete-Polymer Composites,” Advanced Cement Based Materials, Vol. 5, No. 2, 1997, pp. 31-40. doi:10.1016/S1065-7355(96)00005-3

[3] D. W. Fowler, "Polymers in Concrete: A Vision for the 21st Century," Cement and Concrete Composites, Vol. 21, No. 5-6, 1999, pp. 449-452. doi:10.1016/S0958-9465(99)00032-3

[4] Y. W. Choi, Y. J. Kim, H. C. Shin and H. Y. Moon, “An Experimental Research on the Fluidity and Mechanical Properties of High-Strength Lightweight Self-Compacting Concrete," Cement and Concrete Research, Vol. 36, No. 9, 2006, pp. 1595-1602.

doi:10.1016/j.cemconres.2004.11.003

[5] E. Yasar, C. D. Atis, A. Kilic and H. Gulsen, "Strength Properties of Lightweight Concrete Made with basaltic Pumice and Fly Ash,” Materials Letters, Vol. 57, No. 15, 2003, pp. 2267-2270. doi:10.1016/S0167-577X(03)00146-0

[6] J. A. Rossignolo, M. V. C. Agnesini and J. A. Morais, "Properties of High-Performance LWAC for Precast Structures with Brazilian Lightweight Aggregate," Cement and Concrete Composites, Vol. 25, No. 1, 2003, pp. 77-82. doi:10.1016/S0958-9465(01)00046-4

[7] ECO PET, 2007. http://www.ecopet.eu/Domino_english/ecopet.htm

[8] The Korea Institute of Resources Recycling, “The Korean
Institute of Resources Recycling, Recycling Handbook,” The Korea Institute of Resources Recycling, Seoul, 1999.

[9] T. Ochi, S. Okubo and K. Fukui, "Development of Recycled PET Fiber and Its Application as Concrete-Reinforcing Fiber," Cement and Concrete Composites, Vol. 29, No. 6, 2007, pp. 448-455.

doi:10.1016/j.cemconcomp.2007.02.002

[10] M. Batayneh, M. Iqbal and A. Ibrahim, "Use of Selected Waste Materials in Concrete Mixes,” Waste Management, Vol. 27, No. 12, 2007, pp. 1870-1876. doi:10.1016/j.wasman.2006.07.026

[11] O. Y. Marzouk, R. M. Dheilly and M. Queneudec, "Valorization of Post-Consumer Waste Plastic in Cementitious Concrete Composites," Waste Management, Vol. 27, No. 2, 2007, pp. 310-318. doi:10.1016/j.wasman.2006.03.012

[12] S. C. Kou, G. Lee, C. S. Poon and W. L. Lai, "Properties of Lightweight Aggregate Concrete Prepared with PVC Granules Derived from Scraped PVC Pipes,” Waste Management, Vol. 29, No. 2, 2009, pp. 621-628. doi:10.1016/j.wasman.2008.06.014

[13] Y. W. Choi, D. J. Moon, Y. J. Kim and M. Lachemi, "Characteristics of Mortar and Concrete Containing Fine Aggregate Manufactured from Recycled Waste Polyethylene Terephthalate Bottles,” Construction and Building Materials, Vol. 23, No. 8, 2009, pp. 2829-2835. doi:10.1016/j.conbuildmat.2009.02.036

[14] S. Akçaözoglu, C. D. Atis and K. Akçaözoglu, “An Investigation on the Use of Shredded Waste PET Bottles as Aggregate in Lightweight Concrete," Waste Management, Vol. 30, No. 2, 2010, pp. 285-290.

doi:10.1016/j.wasman.2009.09.033

[15] M. Frigione, "Recycling of PET Bottles as Fine Aggregate in Concrete,” Waste Management, Vol. 30, No. 6, 2010, pp. 1101-1106. doi:10.1016/j.wasman.2010.01.030

[16] J. M. L. Reis, R. Chianelli Jr., J. L. Cardoso and F. J. V. Marinho, "Effect of Recycled PET in the Fracture Mechanics of Polymer Mortar," Construction Building Materials, Vol. 25, No. 6, 2011, pp. 2799-2804. doi:10.1016/j.conbuildmat.2010.12.056

[17] J. I. Bhatty, D. Dollimore, G. A. Gamlen, R. J. Mangabhai and H. Olmez, "Estimation of Calcium Hydroxide in OPC, OPC/PFA and OPC/PFA Polymer Modified Systems," Thermochimica Acta, Vol. 106, 1986, pp. 115-123. doi:10.1016/0040-6031(86)85122-X

[18] V. S. Ramachandra, "Differential Thermal Method of Estimating Calcium Hydroxide in Calcium Silicate and Cement Pastes," Cement and Concrete Research, Vol. 9, No. 6, 1979, pp. 677-684. doi:10.1016/0008-8846(79)90062-0

[19] M. U. K. Afridi, Y. Ohama, M. Z. Iqbal and K. Demura, "Morphology of $\mathrm{Ca}(\mathrm{OH})_{2}$ in Polymer-Modified Mortars and Effect of Freezing and Thawing Action on Its Stability," Cement and Concrete Composites, Vol. 12, No. 3, 1990, pp. 163-173. doi:10.1016/0958-9465(90)90017-R

[20] A. S. Benosman, H. Taibi, M. Mouli, M. Belbachir and Y. Senhadji, "Diffusion of Chloride Ions in Polymer-Mortar 
Composites (PET),” Journal of Applied Polymer Science, Vol. 110, No. 3, 2008, pp. 1600-1605. doi:10.1002/app.28587

[21] A.S. Benosman, H. Taibi, M. Mouli, M. Belbachir and Y. Senhadji, "Resistance of Polymer (PET)—Mortar Composites to Aggressive Solutions," International Journal of Engineering Research in Africa, Vol. 5, No. 1, 2011, pp. 1-15. doi:10.4028/www.scientific.net/JERA.5.1

[22] J. Dweck, P. M. Buchler, A. C. V. Coelho and F. K. Cartledge, "Hydration of a Portland Cement Blended with Calcium Carbonate,” Thermochimica Acta, Vol. 346, No. 1-2, 2000, pp. 105-113. doi:10.1016/S0040-6031(99)00369-X

[23] C. J. Fordham and I. J. Smalley, "A Simple Thermogravimetric Study of Hydrated Cement," Cement and Concrete Research, Vol. 15, No. 1, 1985, pp. 141-144. doi:10.1016/0008-8846(85)90019-5

[24] S. Tsivilis, G. Kakali, E. Chaniotakis and A. Souvaridou, "A Study on the Hydration of Portland Limestone Cement by Means of TG," Journal of Thermal Analysis and Calorimetry, Vol. 52, No. 3, 1998, pp. 863-870. doi:10.1023/A:1010139312958

[25] R. Vedalakshmi, A. Sundara Raj, S. Srinivasan, and K. Ganesh Babu, "Quantification of Hydrated Cement Products of Blended Cements in Low and Medium Strength Concrete Using TG and DTA Technique,” Thermochimica Acta, Vol. 407, No. 1-2, 2003, pp. 49-60. doi:10.1016/S0040-6031(03)00286-7

[26] M. U. K. Afridi, Y. Ohama, M. Z. Iqbal and K. Demura, "Behavior of $\mathrm{Ca}(\mathrm{OH})_{2}$ in Polymer-Modified Mortars," The International Journal Cement Composites and Lightweight Concrete, Vol. 11, No. 4, 1989, pp. 235-244. doi:10.1016/0262-5075(89)90104-8

[27] EN 196-3, "Methods of Testing Cement-Part 3: Determination of Setting Time and Soundness," Comité Européen de Normalisation, Brussels, 1995.
[28] D. A. Silva, H. R. Roman and P. J. P. Gleize, “Evidences of Chemical Interaction between EVA and Hydrating Portland Cement," Cement and Concrete Research, Vol. 32, No. 9, 2002, pp. 1383-1390. doi:10.1016/S0008-8846(02)00805-0

[29] H. F. W. Taylor, "Studies on the Chemistry and Microstructures of Cement Pastes," Proceedings of the British Ceramic Society, Vol. 35, 1984, pp. 65-82.

[30] D. B. Kopil'skii, M. Yu. Butt and V. M. Kolbasov, "Question of the Composition and Properties of Portlandite in Hydrated Portland Cements," Soviet Physics-Crystallography, Vol. 13, No. 6, 1969, pp. 945-948.

[31] L. Ben-Dor, C. Heitner-Wirguin and H. Diab, “The Effect of Ionic Polymers on the Hydratation of $\mathrm{C}_{3} \mathrm{~S}$," Cement and Concrete Research, Vol. 15, No. 4, 1985, pp. 681686. doi:10.1016/0008-8846(85)90069-9

[32] A. E. F. de. S. Almeida and E. P. Sichieri, "Mineralogical Study of Polymer Modified Mortar with Silica Fume," Construction and Building Materials, Vol. 20, No. 10, 2006, pp. 882-887. doi:10.1016/j.conbuildmat.2005.06.029

[33] A. Benazzouk, O. Douzane, T. Langlet, K. Mezreb, J. M. Roucoult and M. Quéneudec, "Physico-Mechanical Properties and Water Absorption of Cement Composite Containing Shredded Rubber Wastes," Cement and Concrete Composites, Vol. 29, No. 10, 2007, pp. 732-740. doi:10.1016/j.cemconcomp.2007.07.001

[34] A. S. Benosman, "Mechanical Performance and Durability of Cementitious Materials Modified by adding polymer (PET),” Ph.D. Thesis, University of Oran, Oran, 2010.

[35] S. Martínez-Ramírez, "Influence of $\mathrm{SO}_{2}$ Deposition on Cement Mortar Hydration," Cement and Concrete Research, Vol. 29, No. 1, 1999, pp. 107-111. doi:10.1016/S0008-8846(98)00183-5 